\title{
Effect of reciprocal inhibition and post isometric relaxation; types of muscle energy technique in Piriformis syndrome - A comparative study
}

\author{
Gopal Nambi \\ Department of Physical Therapy and Rehabilitation, Prince Sattam Bin Abdul Aziz University, Al-Kharj, Saudi Arabia
}

\begin{abstract}
Background: Piriformis syndrome (PS) is a neuromuscular condition characterized by hip and buttock pain and may refer to lower back and thigh. Muscle Energy technique involves two techniques such as Reciprocal Inhibition (RI) and Post Isometric Relaxation (PIR) in treatment of pain. Hence the aim of the study was to compare the effects of Reciprocal Inhibition and Post isometric relaxation in Piriformis syndrome.
\end{abstract}

Methods: 64 subjects were divided into 3 groups by random allocation method. Group A, (n=15) subjects received Reciprocal Inhibition, Group B (n=15) received Post isometric relaxation and Group C, $(n=15)$ received Conventional intervention only. Treatment last for 12 sessions over two week period. Pain Intensity, Hip ROM and Functional Disability were measured at baseline and at the end of 12 th treatment session.

Results: At the end of 12 th session the inter group comparison of pain intensity, Hip Abduction, Internal Rotation and functional disability score revealed significant difference $(p=0.000)$. The intra group comparison of VAS, Hip Abduction, Hip Internal rotation and LEFS score shows significant difference ( $<<0.05$ ) in all groups $(\mathrm{P}=0.000)$.

Discussion: Strengthening of hip musculature through PIR may help in correction of abnormal movement pattern \& minimize stress on piriformis thus reduces compression on sciatic nerve. This occurs due to stimulation of stretch receptors. These receptors react to overstretching of muscle by inhibiting further muscle contraction.

Conclusion: Program consists of Post Isometric Relaxation is more effective in reducing pain, improving hip range of motion \& functional outcome in participants with piriformis syndrome.

\section{Introduction}

Piriformis syndrome (PS) is a neuromuscular condition characterized by hip and buttock pain and may result in referred pain in the lower back and thigh [1,2]. PS may occur due to any abnormality such as shortening, spasm, hypertrophy or inflammation of piriformis muscle or any anatomic variation of this muscle that results in compression of sciatic nerve [3]. Incidence rate for PS among patients with low back pain are $5 \%-36 \%[1,4]$. PS is more common in women than men with a ratio of $6: 1[1,5-7]$.

Piriformis occupies a central position in the buttock, where it lies in the same plane as gluteus medius. It originates from 3 different sites 1 st from the anterior surface of the sacrum by three digitations (S2$4),[1,8,9] 2$ nd from the gluteal surface of the ilium near the posterior inferior iliac spine and 3rd from the capsule of the adjacent sacroiliac joint, from the upper part of the pelvic surface of the sacrotuberous ligament. The muscle is inserted to the medial side of the upper border of the greater trochanter of the femur. Vascular supply of this muscle is superior gluteal artery in buttock and lateral sacral artery in pelvis. The muscle is innervated with the branches from L5, S1-2. Piriformis works as external rotator when thigh is extended \& abductor when thigh is flexed [9]. The piriformis muscle is in close relationship with both the sacroiliac joint and the sciatic nerve $[6,10]$. The relationship between piriformis and the sciatic nerve is variable. The undivided nerve may emerge above the muscle or through the muscle. The major divisions of the nerve may lie either side of the muscle, or (the most common variant) one division passes between the heads of a divided muscle and one division either above or below. 9 In about $15 \%$ of the population, the sciatic nerve, all or in part, passes through the piriformis muscle rather than below it [11].

Based on causes PS is classified into two types: Primary PS (< $15 \%)[1,8]$ have an anatomic cause such as split piriformis muscle or split sciatic nerve. Secondary PS occurs as a result of a precipitating cause, including trauma (approx. 50\%), ischemic mass effect, and local ischemia. The trauma is usually not dramatic and may occur several months before the initial symptoms. Trauma to the buttock leads to pain-spasm-inflammation- Irritation cycle. The stretched and inflamed piriformis muscle may compress the sciatic Nerve [1].

Patient of PS usually complain of Pain while sitting, standing, or lying longer than 15 to 20 minutes which may or may not radiate from

Correspondence to: Gopal Nambi, Asstistant Professor, Department of Physical Therapy and Rehabilitation, Prince Sattam Bin Abdul Aziz University, Al-Kharj, Saudi Arabia, E-mail: physio_gopal@rediffmail.com

Key words: Piriformis Syndrome, Reciprocal Inhibition (RI), Post Isometric Relaxation (PIR), visual analog scale, Lower extremity functional score

Received: February 03, 2018; Accepted: February 24, 2018; Published: February 28,2018 
sacrum through gluteal area and posterior aspect of thigh. Complain does not completely relieve with any change in position. Patient may have difficulty in walking. Patient may also complain of Numbness in foot, Abdominal, pelvic, and inguinal pain and Pain with bowel movements. Dyspareunia in women may be seen $[1,8,12]$.

PS is primarily determined clinically therefore a thorough history and a comprehensive physical examination plays an important role [6]. Possible finding in a patient with PS are Tenderness in region of sacroiliac joint, greater sciatic notch, and piriformis muscle. There will be Asymmetrical weakness in affected limb. Positive Finding of Piriformis test, sign of Pace and Nagel, Freiberg sign, Beatty test, Exacerbation of pain in the "FAIR" position Limited medial rotation of ipsilateral lower extremity, Tonic external rotation of the hip and in chronic cases there may be ipsilateral short leg \& Gluteal atrophy [1,8,11-15]. The differential diagnosis of PS includes the causes of low back pain and sciatica [16].

Management of PS includes both surgical (surgical release of the piriformis and decompression of the sciatic nerve) and non-surgical (pharmacological and therapeutic interventions) interventions. Physiotherapeutic interventions include stretching, massage, biomechanical abnormality correction, hip abductor strengthening, core stability exercises, soft tissue and joint mobilization, myofascial release, proprioceptive neuromuscular facilitation (PNF), Muscle energy technique (MET) and electrotherapeutic modalities such as ultrasound [1,6,7,17-21].

The current study used MET and Conventional Interventions (CI) includes moist heat, piriformis muscle stretching \& hip abductor strengthening. Conservative treatment of PS focuses mainly on symptomatic relief of pain [22-25]. MET involve the use of two physiological phenomena: Post Isometric Relaxation (PIR) and Reciprocal Inhibition (RI) in treatment of musculoskeletal disorders such as pain, muscle spasm and muscle shortening $[23,24]$.

This study was done to find a suitable conservative physiotherapeutic management of PS and also to determine and to compare the effects of different MET techniques i.e. RI-MET \& PIR-MET in the management of PS, towards pain, ROM and function of hip joint.

\section{Material and methodology}

This study was conducted at the musculoskeletal physiotherapy OPD of C. U. Shah Physiotherapy College, Surendranagar, Gujarat. Study Design: Experimental study (interventional comparative) design. Subjects: A total number of 64 subjects suffering from back \& buttock pain were screened by completing a detailed orthopedic physical assessment out of which 45 subjects who fulfill the study criteria were recruited to volunteer in this randomised controlled study. Selected patients through Random sampling method were divided into 3 groups by random allocation method. Group A, 15 patients had received RI MET \& Conventional intervention (moist heat, piriformis stretching, and hip abductor strengthening). Group B, 15 patients had received PIR MET \& Conventional intervention. Group C, 15 patients had received Conventional intervention only. Treatment program, lasting For 12 session (6 sessions/week) over two week period. Treatment techniques were approved by the institutional scientific and ethical committee with reference no CUSPC/Ethical/08/12 and the study was conducted according to the ethical guidelines and principles of the Declaration of Helsinki.

\section{Inclusion criteria}

Participants from age group 25-45 years, both genders, Onset of pain not $>2$ weeks, Single incidence, Decreased hip medial rotation ROM (knee in 00 flexion), Unilateral involvement of piriformis muscle, VAS : 3-6, \& Any three positive test among piriformis test, beatty test, Freiberg test, FAIR test, Sign of Pace \& Nagel, tonic external rotation of hip [1,8,11-13].

\section{Exclusion criteria}

Any pathology or recent injury around hip, knee and SI joint, radiating pain from spine, SI joint and hip, Pain due to neurological, spinal or pelvic origin, Limb length discrepancy, Trigger point in the piriformis muscle, SI joint disorder, Fracture of femur \& hip joint dislocation, any postural abnormality/ deformity $[1,6,8,14,16]$.

\section{Materials}

Evaluation form, Consent form, Universal goniometer (360o), Moist pack, Weight cuff (0.5-1.5 kg), Patient Log Book

\section{Methods of patient evaluation}

After explaining the objectives and procedures of the study, informed consent form was obtained from all the subjects. Participants' provided their demographic details including gender, age, height and weight, BMI prior to the study. All Outcome measures were taken at baseline and at the end of 12th treatment session. A log book was provided to patients to record on a daily basis whether they carry out the exercises at home for 2 week period.

\section{Pain intensity assessment}

Visual analogue scale (VAS) was used to measure pain intensity. A $10 \mathrm{~cm}$ line marked with number $0 \& 10$ was used where 0 symbolizes no pain and 10 is maximum pain tolerable [26].

Hip ROM: Universal (3600) goniometer was used to measure abduction and internal rotation ROM of hip [27,28].

Measures of Functional Disability: Function of hip joint \& relative changes in lower limb were recorded using Lower Extremity Functional Scale (LEFS). LEFS is a questionnaire containing 20 questions with total score of 80 points about a person's ability to perform everyday tasks. Items include difficulty level in performing everyday task. Each item is rated on a Likert scale where Lower score indicates greater disability and vice versa [29].

\section{Treatment intervention}

\section{Conventional intervention}

All the patients were treated with moist heat application over piriformis muscle, stretching of piriformis muscle (3 repetitions with 30 seconds hold) \& Strengthening exercises for hip abductors (3 sets; 10 times per set; with the use of weight cuffs).

\section{Muscle energy technique}

Patient was lying in supine lying position, with the treated leg is placed into flexion at the hip and knee, so that the foot rests on the table lateral to the contra lateral knee (the leg on the side to be treated is crossed over the other). Therapist places one hand on the contra lateral ASIS to prevent pelvic motion, while the other hand is placed against the lateral flexed knee as this is pushed into resisted abduction to contract piriformis (PIR MET) or into resisted adduction to contract 
antagonists or to inhibit piriformis muscle (RI MET). The starting position will be the 1st sign of resistance towards end range. Therapist Force will be same as patient's force. Initial effort is approx $20 \%$ of patient's strength. Duration of contraction is 7-10 seconds with three repetitions.

\section{Statistical analysis}

All statistical analysis was done using SPSS 16.0 software for windows. Descriptive analysis was obtained by mean and standard deviations. Kolmogorov Smirnov Test was used for data normality test which was found to be normally distributed in all the variables. Intra group comparison of outcome measures was done using T Test (Paired Sample Test). Intergroup comparison of outcome measures was done using Oneway ANOVA. Bonferroni post hoc analysis was performed for multiple inter group comparison. Confidence interval were set at $95 \%, \mathrm{p}=0.05$ for all the analysis.

\section{Result}

Table 1 shows the descriptive Statistics for the mean Age, Height, Weight, BMI \& Duration of Symptoms of Group A, B, \& C. The Table 2 shows the inter group comparison of VAS, Hip Abduction ROM, Internal Rotation ROM \& LEFS score at baseline and at the end of 12th treatment session in Group A, B \& C. The analysis to test the initial difference between the groups for VAS, Hip Abduction ROM, Internal Rotation ROM \& LEFS baseline scores revealed no significant difference $(\mathrm{p}=0.795,0.972,0.897,0.881)$.

Post intervention at the end of 12 th treatment session the inter group comparison of VAS, Hip Abduction ROM, Internal Rotation ROM \& LEFS score revealed significant difference $(p=0.000)$.

The Table 2 also shows the intra group comparison of VAS, Hip Abduction ROM, Internal Rotation ROM \& LEFS Score in group A, B $\&$ C. The intra group comparison of VAS, Hip Abduction ROM, Hip IR ROM \& LEFS score shows significant difference $(p<0.05)$ in all groups (Group A: $\mathrm{P}=0.000$; Group B: $\mathrm{P}=0.000$ and Group $\mathrm{C}: \mathrm{P}=0.000$ ) (Figure 1 and 2).

Comparison of mean of difference of post intervention scores between Groups A, B \& C was done through Post-Hoc analysis Bonferroni test. There is significant difference between VAS, Hip

Table 1. Descriptive Statistics for the mean Age, Height, Weight, BMI \& Duration of Symptoms of Group A, B, \& C

\begin{tabular}{|c|c|c|c|c|c|}
\hline & Age (Years) & Height (cm) & $\begin{array}{c}\text { Weight } \\
(\mathbf{K G})\end{array}$ & $\begin{array}{c}\text { BMI } \\
\left(\mathbf{k g} / \mathbf{m}^{2}\right)\end{array}$ & $\begin{array}{c}\text { Duration of } \\
\text { Symptoms }\end{array}$ \\
\hline Group A(n=15) & $33.86 \pm 6.04$ & $159.17 \pm 5.69$ & $54.10 \pm 5.18$ & $21.41 \pm 1.74$ & $6.06 \pm 2.12$ \\
\hline Group B(n=15) & $34.73 \pm 6.00$ & $157.13 \pm 7.17$ & $52.90 \pm 7.03$ & $21.42 \pm 1.67$ & $6.20 \pm 2.04$ \\
\hline Group C(n=15) & $34.13 \pm 5.92$ & $157 \pm 6.25$ & $51.93 \pm 6.45$ & $20.99 \pm 1.84$ & $6.26 \pm 2.43$ \\
\hline p- value & 0.921 & 0.587 & 0.641 & 0.752 & 0.962 \\
\hline
\end{tabular}

Table 2. Descriptive statistics of the VAS, Hip Abduction and Internal Rotation ROM \& LEFS Score

\begin{tabular}{|c|c|c|c|c|c|}
\hline & & Group A & Group B & Group C & $\begin{array}{c}\text { p-value } \\
\text { (inter) }\end{array}$ \\
\hline \multirow{2}{*}{ VAS Score } & Pre Treatment & $4.13 \pm 0.99$ & $4 \pm 1.13$ & $4.26 \pm 1.09$ & 0.795 \\
\cline { 2 - 6 } & Post Treatment & $2.06 \pm 0.88$ & $1.33 \pm 0.89$ & $3.0 \pm 0.92$ & 0.000 \\
\hline \multirow{2}{*}{$\begin{array}{c}\text { Hip ABD } \\
\text { ROM }\end{array}$} & Pre Treatment & $19 \pm 2.03$ & $19.13 \pm 2.50$ & $19.20 \pm 2.39$ & 0.972 \\
\cline { 2 - 6 } & Post Treatment & $31.33 \pm 2.43$ & $36.80 \pm 2.33$ & $27.13 \pm 1.55$ & 0.000 \\
\hline \multirow{2}{*}{ Hip IR ROM } & Pre Treatment & $15.13 \pm 2.99$ & $15.60 \pm 2.99$ & $15.20 \pm 2.90$ & 0.897 \\
\cline { 2 - 6 } & Post Treatment & $34.73 \pm 2.49$ & $40 \pm 1.55$ & $29.26 \pm 2.81$ & 0.000 \\
\hline \multirow{2}{*}{ LEFS Score } & Pre Treatment & $13.66 \pm 3.33$ & $13.33 \pm 2.38$ & $13.86 \pm 2.97$ & 0.881 \\
\cline { 2 - 6 } & Post Treatment & $60.20 \pm 3.60$ & $71.13 \pm 3.35$ & $40.60 \pm 3.35$ & 0.000 \\
\hline
\end{tabular}

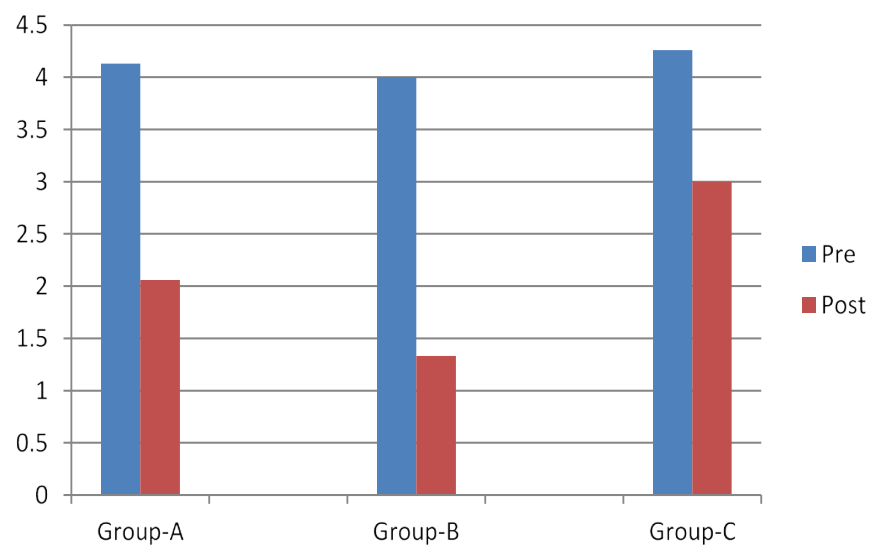

Figure 1. Descriptive statistics of the VAS between group-A, B and C.

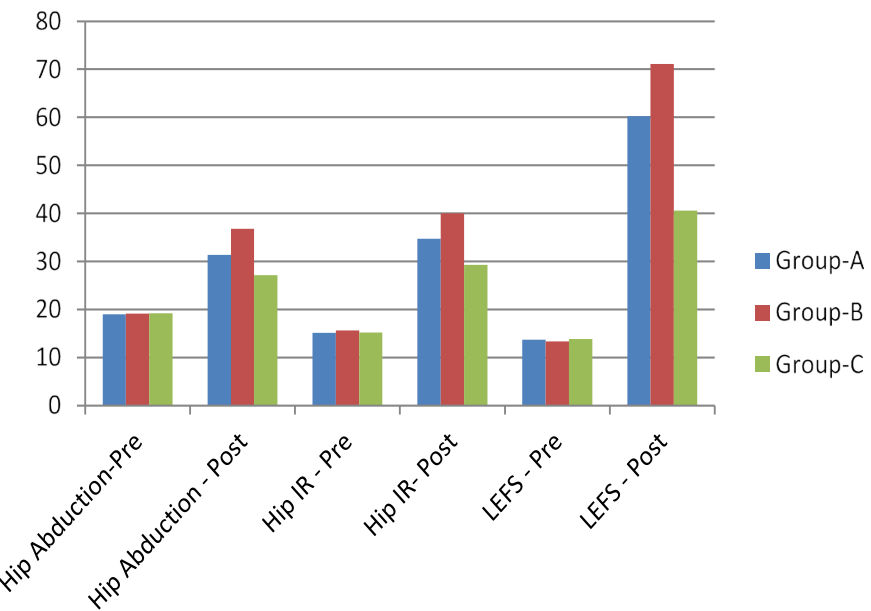

Figure 2. Descriptive statistics of the Hip Abduction and Internal Rotation ROM \& LEFS Score between group-A, B and C.

Abduction ROM, Hip IR ROM \& LEFS Score of Group A \& Group C with p value of $0.021,0.00,0.00,0.00$ (i.e. $<0.05$ ), Group B \& Group $\mathrm{C}$ with $\mathrm{p}$ value of 0.000 (i.e. $<0.05$ ) for all the groups. There was no significant difference between VAS Score of Group A \& Group B with the $p$ value of 0.095 (i.e. $>0.05$ ). There was significant difference between other outcome such as Hip Abductor ROM, Hip IR ROM \& LEFS of Group A \& B with the p value of $0.00,0.00 \& 0.00$ (i.e. > 0.05). However, it can be observed that largest significant change in all the outcome measures in Group B as compared to Group A \& Group C.

\section{Discussion}

Total 45 (27 (60\%) female \& 18 (40\%) male) patients with PS were divided into three groups with 15 patients in each group. All the patients were treated with conventional interventions added with RI-MET in group A \& PIR-MET in group B. Outcome measures included VAS, Hip abduction and internal rotation ROM by goniometry and LEFS were measured at baseline and at the end of 12th treatment session. All groups were homogenous in their demographic details as well as in baseline outcome measures. For finding inter- and intra- group comparison of scores of outcome measures one way ANOVA and t-test were used respectively. Intra group comparison of baseline and post 12 session score was done. The results show significant improvement in each group. There was a tendency for both the experimental groups (Group A \& B) to perform better than control group in almost all the outcomes. 
Results show that all the interventions were effective in reducing pain, improving ROM and functional outcome in patients. Multiple comparisons for mean of difference of 12 treatment session was done for all the outcome measures using Bonferroni post hoc test to justify the intergroup difference for each outcome measure. The results of post hoc analysis suggested that after 12 session of intervention Group B show greater improvement in all the outcome measures.

The $\%$ changes in outcome measures were significantly different between the Groups. $26.07 \%, 30.79 \%$ \& $18 \%$ reduction of pain, 47.42 $\%, 68.75 \%$ \& $30.73 \%$ improvement in ABD ROM, $65.61 \%, 82.99$ $\%$ \& $47.18 \%$ improvement in IR ROM \& $70.15 \%, 86.69 \%$ \& 40.42 $\%$ improvement of functional outcome (LEFS Score) was noted in Group A, B \& C respectively. Results show that PIR-MET along with CI was more effective than RI-MET with $\mathrm{CI}$ in reducing pain $(4.72 \%$ difference), improving ABD ROM (21.33\% difference), IR ROM (17.38 $\%$ difference) $\&$ functional outcome ( $16.54 \%$ difference).

Hot pack usually gets absorbed more in tissues with high fluid content especially muscle. Piriformis muscle being a deep seated muscle must have got adequate heating effects, which could have reduced inflammatory process and subsequently has reduced spasm and increased flexibility of this muscle.

Strengthening of hip musculature may help in correction of abnormal movement pattern \& minimize stress on piriformis thus reduces compression on sciatic nerve. Improved performance of hip musculature helps to decrease the demand on the piriformis through agonist activity and prevent hip motion that would cause increased strain on the piriformis [2].

PIR refers to the subsequent reduction in tone of the agonist muscle after isometric contraction. This occurs due to stretch receptors (Golgi tendon organs). These receptors react to overstretching of muscle by inhibiting further muscle contraction. This is naturally a protective reaction, preventing rupture and has a lengthening effect due to the sudden relaxation of the entire muscle under stretch. RI refers to the inhibition of the antagonist muscle when agonist contract isometrically. This happens due to stretch receptors within the agonist muscle fibres - muscle spindles. Muscle spindles work to maintain constant muscle length by giving feedback on the changes in contraction, in this way muscle spindles play a part in proprioception. In response to being stretched, muscle spindles discharge nerve impulses, which increase contraction, thus preventing over-stretching [30]. Previous studies also had shown greater relief in pain; spasm and tenderness in the affected muscle with MET applied while the muscle is in a stretched position [31]. Probably all the above effect of MET have helped in resolution of pathological changes of piriformis muscle and decrease stress on the sciatic nerve by piriformis muscle. Thus, the subjects in group A \& B who received MET with CI had shown statistically significant changes in outcome measures. CI alone must not have contributed much to improve the symptoms of the patients in the Group C.

In this study more importance is given to privacy and emotional aspects of patients care by avoiding exposure of treated area. Advantage of using MET is of having active participation of the patient during the course of treatment as well as allowing progression in treatment as per their comfort. This study was done on acute cases of PS further studies should be done with the same treatment protocol for chronic cases of PS. There is no provision of long term follow up in this study further studies should include long term follow up.

\section{Conclusion}

The results indicate that the treatments in all groups are effective in reducing pain, improving Range of Motion (ROM) and functional outcome in subjects with Piriformis Syndrome (PS). However, the subjects in Group B, Who received Post Isometric Relaxation Muscle Energy Technique (PIR-MET) along with CI, showed more improvement in outcome measures than Group A and C, suggesting the treatment program consists of Post Isometric Relaxation is more effective in reducing pain, improving hip range of motion \& functional outcome in participant with piriformis syndrome.

\section{Conflict of interest}

The authors declare that they have no competing interests.

\section{Funding}

The authors thankful to the Deanship of scientific research C.U. Shah Physiotherapy college for funding this study with ref no. CUSPC/ Ethical/08/12. The views of this study are purely responsible to the author, not responsible to anything.

\section{Acknowledgement}

The author would like to thank all the subjects and physiotherapists who have coordinated and participated in the study, as well as acknowledgement to Dr. Dipika for helping to interpret the data and editing the manuscript.

\section{References}

1. Boyajian-O'Neill LA, McClain RL, Coleman MK, Thomas PP (2008) Diagnosis and management of piriformis syndrome: an osteopathic approach. J Am Osteopath Assoc 108: 657-664. [Crossref]

2. Tonley JC1, Yun SM, Kochevar RJ, Dye JA, Farrokhi S, et al. (2010) Treatment of an individual with piriformis syndrome focusing on hip muscle strengthening and movement reeducation: a case report. J Orthop Sports Phys Ther 40: 103-111. [Crossref]

3. Tibor LM, Sekiya JK (2008) Differential diagnosis of pain around the hip joint Arthroscopy 24: 1407-1421.[Crossref]

4. Meknas K, Kartus J, Letto JI, Flaten M, Johansen O (2009) A 5-year prospective study of non-surgical treatment of retro-trochanteric pain. Knee Surg Sports Traumatol Arthrosc.

5. Pace JB (1976) Dennis nagle. Piriformis syndrome. West J Med 124: 435-439.

6. Cummings M (2000) Piriformis syndrome. Acupuncture Medicine 18: 108-121.

7. F Cramp, O Bottrell, H Campbell, P Ellyatt, C Smith, et al. (2007) Non-surgical management of piriformis syndrome: a systematic review. Physical Therap Rev 12: 66-72.[Crossref]

8. Dye S, Das S, Bhattacharyya P (2013) Piriformis syndrome: a clinical review. J Evolut Med Dent Sci 2: 2502-2508

9. Gray's anatomy (2008) The anatomical basic of clinical practice, $40^{\text {th }}$ edition

10. Hopayian K, Song F, Riera R (2000) The piriformis syndrome: a report of a systematic review of its clinical features and the methodology developed for a review of case studies. $1^{\text {st }}$ ed. East Anglia.

11. David J Magee (1987) Orthopaedic physical assessment. $5^{\text {th }}$ edition, Missouri. Elsevier Inc.

12. Hopayian K1, Song F, Riera R, Sambandan S (2010) The clinical features of the piriformis syndrome: a systematic review. Eur Spine J 19: 2095-2109. [Crossref]

13. Miller TA, White KP, Ross DC (2012) The diagnosis and management of piriformis syndrome: myths and facts. Can J Neurol Sci 39: 577-583. [Crossref]

14. Keskula DR, Tamburello M (1992) Conservative management of piriformis syndrome. J Athl Train 27: 102-108. [Crossref]

15. Physiopedia (2013) Piriformis syndrome. 
16. Norbury JW, Morris J, Warren KM, Schreiber AL, Faulk C, et al. (2012) Diagnosis and management of piriformis syndrome. Pract Neurol 24-27.

17. Milton JK (2008) Piriformis syndrome. Emedicine 14: 2.

18. Awan WA, Babur MN, Ali S, Janjua UI (2012) Effectiveness of electrotherapy with manual therapy in the treatment of piriformis syndrome. IJRS 1: 16-19.

19. Lowe W (2008) Treating piriformis syndrome. Massage Today 08: 1-5.

20. Kline CM (2007) Piriformis syndrome: controversies continue. JACA 1-7.

21. Reid DC (1992) Problem of the hip, pelvis,and si joint. In: reid (eds.) Sports injury assessment and rehabilitation. $1^{\text {st }}$ ed.: Churchill Livingstone 665-666.

22. Kirschner JS, Foye PM, Jeffrey G (2009) Piriformis syndrome, Diagnosis and treatment. Muscle-nerve 40: 10-18.

23. Chaitow L (2006) Muscle energy techniques. 3rd ed. Elsevier health sciences.

24. Chaitow L (2013) Soft tissue manipulation: diagnostic and therapeutic Potential. 1-34.
25. Khuman PR, Surbala L, Dusad G, Jadeja S, Chandrabharu V (2014) Effect of reciprocal inhibition muscle energy technique in piriformis syndrome: a single case study. IJRSR 5: 1794-1798.

26. Bijur PE, Silver W, Gallagher EJ (2001) Reliability of the visual analogue scale for measurement of acute pain. Acad Emerg Med 8: 1153-1157. [Crossref]

27. Gajdosik RL, Bohannon RW (1987) Clinical measurement of range of motion: review of goniometry emphasizing reliability and validity. Phys Ther 67: 1867-1872. [Crossref]

28. Norkin CC, White DJ (1985) Measurement of joint motion a guide to goniometry. 3rd ed. Philadelphia. E.g. Houghton Mifflin.

29. Binkley JM, Stratford PW, Lott SA, Riddle DL (1999) The lower extremity functional scale (LEFS): scale development, measurement properties, and clinical application; Phys Ther 79: 371-383. [Crossref]

30. Gill Webster. The physiology and application of muscle energy techniques.

31. Lewit K, Simons DG (1984) Myofascial pain relief by post isometric relaxation. Arch Phys Med Rehabil 65: 452-456. [Crossref]

Copyright: ( 2018 Nambi G. This is an open-access article distributed under the terms of the Creative Commons Attribution License, which permits unrestricted use, distribution, and reproduction in any medium, provided the original author and source are credited. 